\title{
Roxas City, the Seafood Capital of the Philippines: Myth or Fact?
}

\author{
I.B. Arcega ${ }^{1}$, S.J.D. Malayang ${ }^{2}$, P.J. Mirasol ${ }^{3} \&$ A.B. Casios $^{4}$

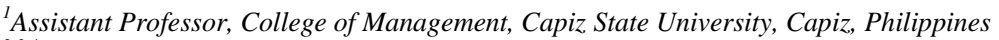 \\ ${ }^{2,3,4}$ Instructor, College of Management, Capiz State University, Capiz, Philippines.

Copyright: (C) 2021 I.B. Arcega et al. This is an open access article distributed under the terms of the Creative Commons Attribution License, which permits unrestricted use, distribution, and reproduction in any medium, provided the original author and source are credited.

The purpose of this study attempts to prove the branding of Roxas City, which is part of the Province of Capiz, like the Seafood Capital of the Philippines. The researchers utilized secondary data from the Fisheries Statistics of the Philippines from 2007 to 2017 through time-series analysis The study was on the determination of the performance of the Province of Capiz in the type of production on Commercial, Marine Municipal, Inland Municipal, and Aquaculture its volume and value at the same time knowing the performance on various species and determine who are the top fisheries producing Provinces by sector from 2007 to 2017. Results of the study revealed that the volume and value in the fishing industry in commercial, marine municipal, inland municipal in the Province of Capiz was decreasing. The researchers observed that the Capiz is not part of the top producing province in the Philippines. However, the volume and value in the aquaculture industry were increasingly focused on different species such as milkfish, mud crab, mussel, oyster, tiger prawn, white shrimp, and endeavor prawn. If the basis of the City of Roxas to become the Seafood Capital of the Philippines is in volume and value across industry types, the claim is a myth.

Keywords: Province of Capiz, Time-series analysis, Fisheries, Commercial, Municipal, Inland municipal and aquaculture.

\section{Introduction}

In 2016, the Philippines ranked $8^{\text {th }}$ among the top fish-producing countries globally, with 4.2 million metric tons of fish, crustaceans, mollusks, and aquatic plants (including seaweeds). The production constitutes $2.1 \%$ of the total world production of 202. 2 million metric tons (FAO Statistics). The Philippines' 0.796 million metric tons aquaculture production of fish, crustaceans, and mollusks in 2016 ranked 11th in the world and a $1.0 \%$ share of the total global aquaculture production of 80.03 million metric tons. In terms of value, the country's aquaculture production of fish, crustaceans, and mollusks has amounted to over 1.79 billion dollars (FAO Statistics). Similarly, the Philippines is the world's 3rd largest producer of aquatic plants (including seaweeds), having produced a total of 1.4 million metric tons or nearly $4.7 \%$ of the total world production of 30.14 million metric tons (FAO Statistics). The fishing industry's contribution to the country's Gross Domestic Products (GDP) was $1.2 \%$ and $1.4 \%$ at current and constant 2000 prices. It translates to P197.23 billion and P122.25 billion for current and constant prices of the country's GDP of P15,806 billion (current prices) and P8,666 billion (constant prices). Roxas City is the self-proclaimed seafood capital of the Philippines. The city serves as the entry point for a fertile agricultural area, exporting the surplus to nearby islands. The town is economically booming because of various industries such as agriculture and aquaculture products.

Roxas City was heavily damaged when Super Typhoon Haiyan, a powerful tropical cyclone that swept the Region in early November 2013 (Pletcher, Kenneth, 2020). The study investigates if Roxas City is still the Seafood Capital of the Philippines through a time-series analysis on volume and value. Also, the researchers want to prove if this branding can bring a competitive advantage over other Provinces in the country and cascade this to the community. Specifically, it sought to answer the following (1) What is the performance (volume and value) of the production in the Province of Capiz in terms of fisheries, commercial, municipal, inland municipal, and aquaculture for the 




Asian Journal of Applied Science and Technology (AJAST)

Volume 5, Issue 3, Pages 213-222, July-September 2021

period covered 2007 to 2017 in volume (in metric tons) and value (in Pesos); (2) What is the performance (volume and value) of the various species in the Province of Capiz for the period covered 2007 to 2017; (3) What is the performance (volume and value) of the production by type of Aquafarm in the Province of Capiz for the year 2007 to 2017 and; (4) What are the top fisheries producing provinces by sector from 2007 to 2017. The study results would benefit the Provincial Government and Roxas City Government, entrepreneurs, people of Capiz, Bureau of Fish and Aquatic Resources (BFAR), higher education institutions, Department of Trade and Industry (DTI), and future researchers. The results will be the basis for policy formulation, revisiting the strategic plan and direction of the City Council, and development of valuable strategies to maintain the volume and value of the fishing industry in the Province of Capiz.

\section{Theoretical Framework}

The study anchored on the BFAR laws and other related laws. System theory and Motivation-Opportunity-Ability (MOA) model, proposed by MacInnis and Jaworski (1989) and MacInnis et al. (1991), who theorized the degree to which people process information by using various combinations of MOA when taking action. According to the MOA model, motivation incorporates readiness, willingness, interest, and the desire to engage in information processing. The opportunity has been conceptualized as to the extent of the situation is conducive to achieving the desired outcome. Ability refers to consumer skills or proficiencies in interpreting brand information from an advertisement (MacInnis et al., 1991). Mainly, opportunity represents the environmental or contextual factors that enable action (Rothschild 1999).

\subsection{The Framework of the Study}

The framework of the study will map the performance, volume, and production in terms of volume and value of fisheries, commercial, inland municipal and aquaculture, various species available in the Province of Capiz.

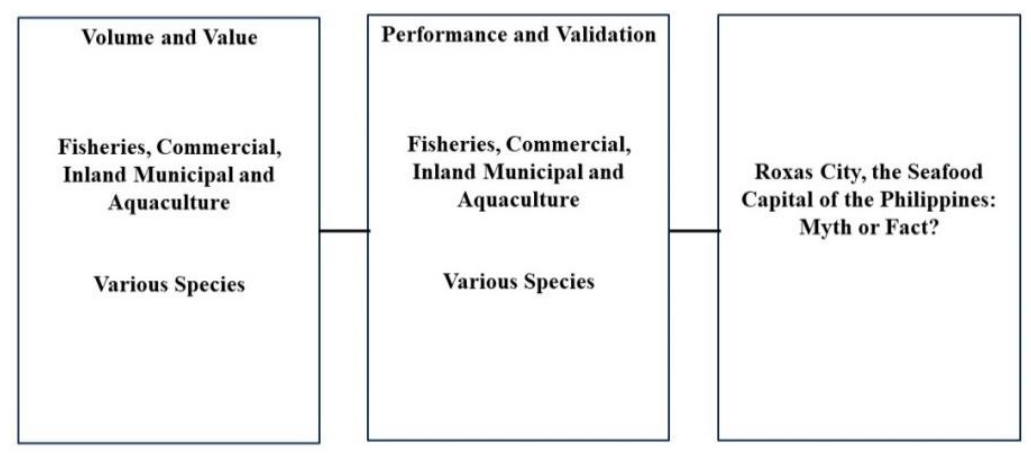

Fig.1. Showing the constructs of the study

\subsection{Scope and Limitation of the Study}

This study focuses on exploring the fishing industry data and tourism of the Province of Capiz. Moreover, to know whether Roxas City is the Seafood Capital of the Philippines. The data use is the consolidation of a Fisheries Statistics report of the Philippines from 2007 to 2017. Data of Roxas City is part of the total number of the Province of Capiz. The analysis of whether Roxas City branding as the Seafood Capital of the Philippines is through the volume and species of the fishing industry produced in the province and validates with various vital informants. 


\section{AJAST}

Asian Journal of Applied Science and Technology (AJAST)

Volume 5, Issue 3, Pages 213-222, July-September 2021

\section{Methodology}

It is a descriptive research design utilizing the quantitative and qualitative methods of gathering the data — using secondary data for analysis. Data used are the Fisheries Statistics of the Philippines from 2007 to 2017 from Luzon to Mindanao. A time series of research was also used in the processing and analyzing the data. They compared the performance of the Province of Capiz to other Provinces in the country.

Researchers validate the results with the key informants for an interview. The informants are the BFAR Officers, Fisherfolks, Roxas City Officials, Roxas City Community, Officers from the Department of Trade and Industry, Business Owners their business is in fishing and restaurant, tourists, and Head of the Higher Education Institutions.

\section{Results and Discussions}

\subsection{Fisheries, Commercial, Inland Municipal, and Aquaculture Production}

The researchers are comparing based on 2007 to 2017, but also analyzed data for future analyses. FIG 2 shows that Capiz was ranked fourth $\left(4^{\text {th }}\right)$ in the fisheries production among five (5) Provinces in the Western Visayas. In the 2017 volume of fisheries production, there were 87,582.82 metric tons.

For the last ten years, the year 2010 reached the highest volume, 104,881.45 metric tons. It implies an increase and decreases in production for eleven (11) years of operation.

It might cause an immediate cause of weather, climate change, and marine diseases.

It was supported by growers, which they encountered water-borne conditions such as red tide that affected aquaculture production impacted the industry due to climate change.

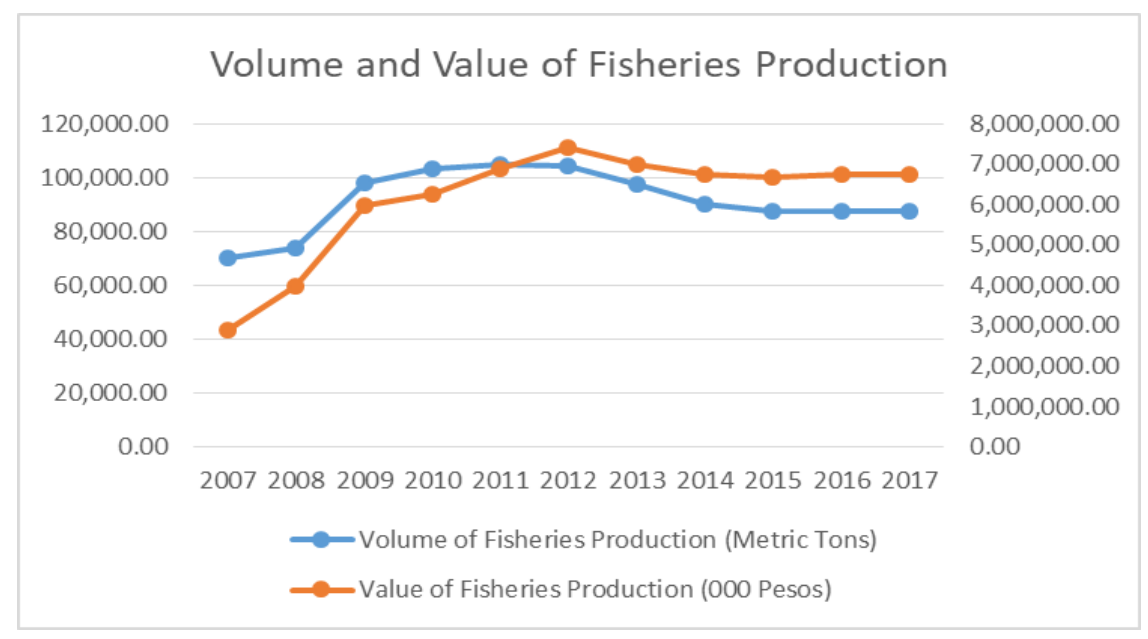

Fig.2. Showing the volume and value of fisheries production

\subsection{Commercial Fisheries}

Fig 3 shows the commercial production of Capiz for the last 11 years. Capiz was ranked third $\left(3^{\text {rd }}\right)$ among six Province in Western Visayas. In 2011, 24,604.65 metric tons produced and its value of 1,530,827.22. It implies that the production volume was decreasing, but other Provinces maintained their production volume in commercial fisheries. 


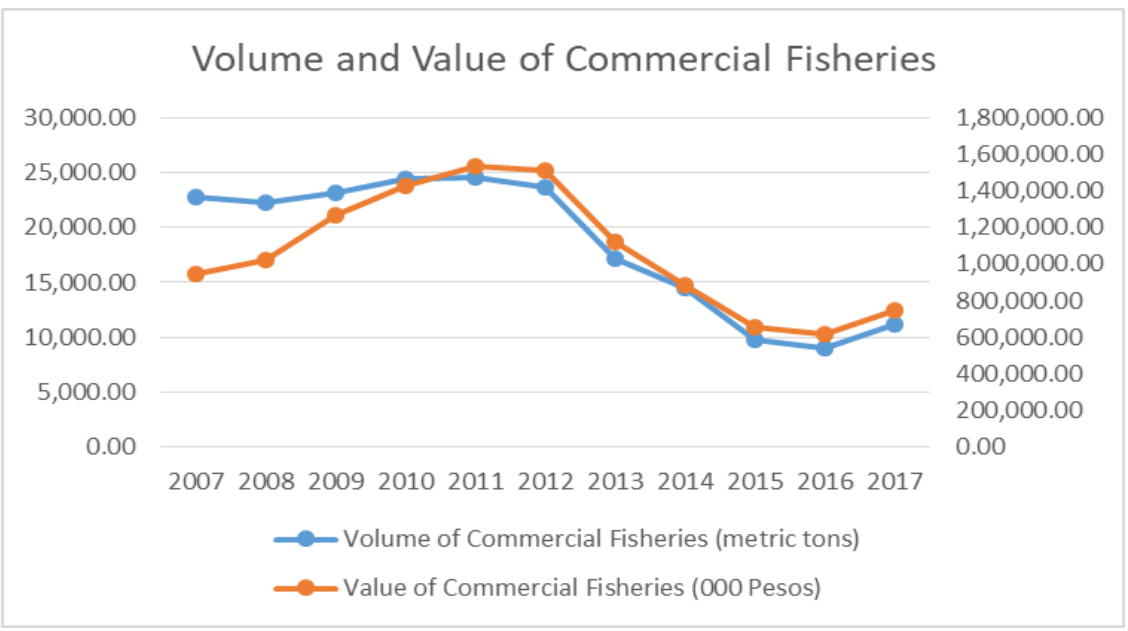

Fig.3. Showing the volume and value of commercial fisheries

Fig 4 shows the volume of production and its value of Municipal Fisheries from 2007 to 2017. In 2010, it was the highest production in the Province of Capiz, which has 38,931.72 metric tons, and 2012 had the highest value of $2,451,745.85$. Furthermore, Capiz was ranked third $\left(3^{\text {rd }}\right)$ among five Provinces in Western Visayas.

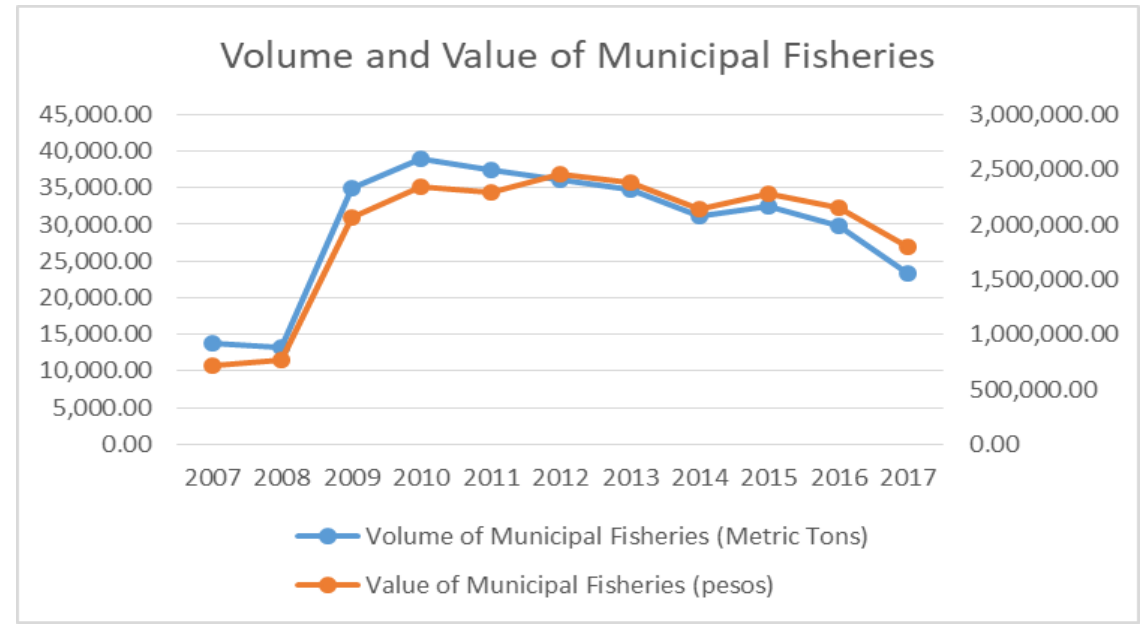

Fig.4. Showing the volume and value of municipal fisheries

\subsection{Inland Municipal Fisheries}

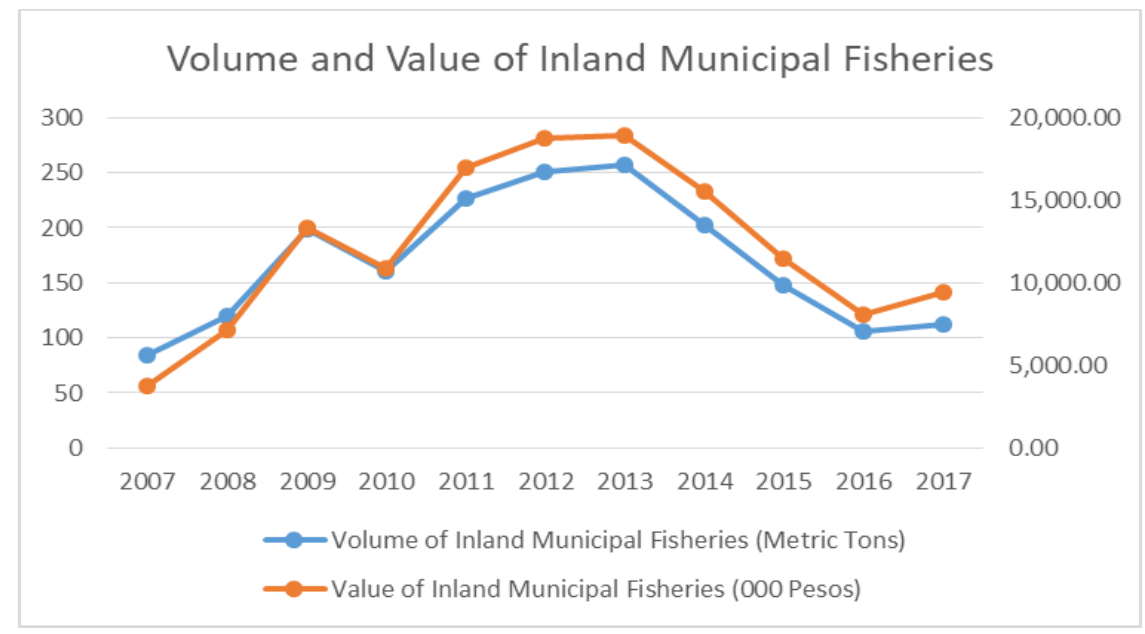

Fig.5. Showing the volume and value of inland municipal fisheries 
Fig 5 shows the volume of production and its value of Municipal Fisheries from 2007 to 2017. In 2013, it was the highest production in the Province of Capiz, which has 256.76 metric tons, and 2012 had the highest value of 18,9471.10. Moreover, Capiz was ranked fifth (5th) among five Provinces in Western Visayas.

\subsection{Aquaculture}

Fig 6 shows the volume of production and its value of Municipal Fisheries from 2007 to 2017. In 2017, it was the highest production in the Province of Capiz, which has 52,957.76 metric tons, and 2017 had the highest value of 4,200,456.92. Furthermore, Capiz was ranked second $\left(2^{\text {nd }}\right)$ among five Provinces in Western Visayas. Based on the data presented, the findings are formulated: (1) the Province of Capiz was not part of the top producing Provinces in the Philippines based on the data analyzed from 2007 to 2017 in Commercial, Marine Municipal, Inland Municipal, and Aquaculture; (2)through the years the Province of Capiz has a declining volume of production based on the fishing industry cited above; (3) the value of the produced was also erratic due to the inflation and deflation experienced by the country; (4) however, on Western Visayas, the Province of Capiz was ranked lower compared to other provinces in the Region. The informants postulate that the Province of Capiz has no organized group related to this kind of industry, which they can adopt best practices to other growers. Moreover, it is noted that the province was affected by various typhoons and other calamities that destroyed the business and its production.

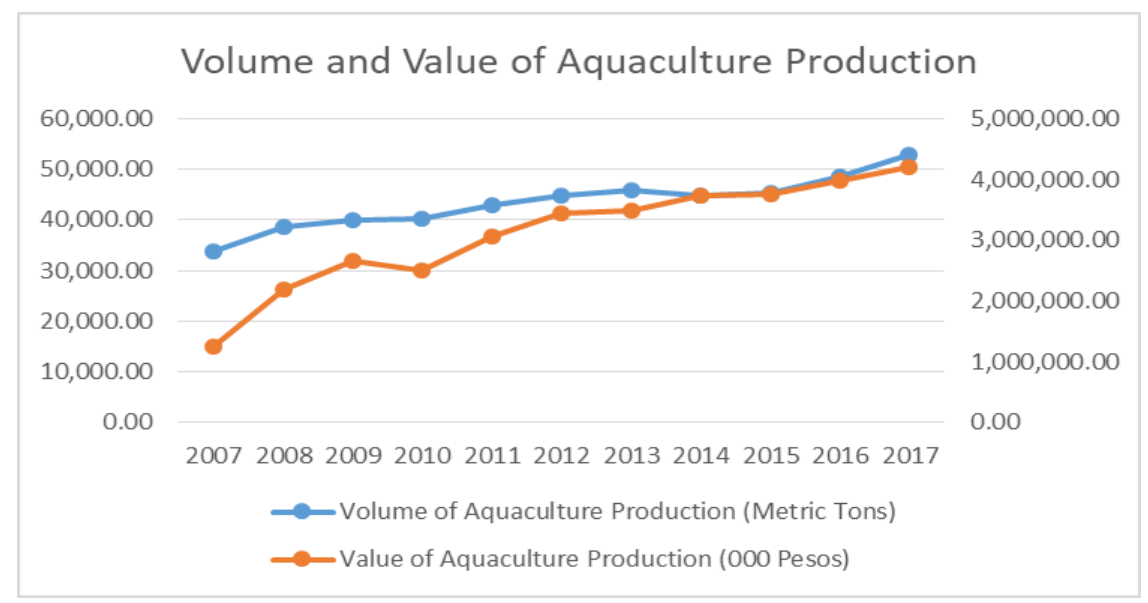

Fig.6. Showing the volume and value of aquaculture production

\subsection{Performance of Different Species Produced in Volume and Value}

The volume and value of anchovies (dilis), Capiz was ranked first $\left(1^{\text {st }}\right)$ in the total produced 2010 has 5,463.76 metric tons and P 237,996.57. It implies that in Capiz, this species is abundant, but the volume is decreasing through the years. For the volume and value of the big-eyed scad (matang-baka). Capiz was ranked first $\left(1^{\text {st }}\right)$ in total produced; in 2015, it has 2,030.63 metric tons and 152,842.37. It implies that in Capiz, this species is abundant, but the volume is decreasing through the years. For the big-eyed tuna (tambakol/bariles). This species is not abundant present in the Province of Capiz. Nevertheless, there was volume produced in 2007, 2008, and 2009, but it is very minimal - the blue crab (alimasag). Capiz was ranked third $\left(3^{\text {rd }}\right)$ in this kind of species produced. In 2011, the total produced was 2,064.17, and in 2017, the highest value was 129,215.21. The volume and value of cavalla (talakitok). Capiz was ranked sixth $\left(6^{\text {th }}\right)$ in this kind of species produced. In 2013, the total grew 50.79 metric tons, and in 2011 highest value was 7,522.52. 


\subsection{Production in Marine Fisheries}

Capiz was ranked third $\left(3^{\text {rd }}\right)$ in the volume and value of the crevalle (salay-salay). In 2016, the total produced was 1,359.21 metric tons, and in 2011, the highest value was 72,533.25. For frimbriated sardines (tunsoy), it was ranked second $\left(2^{\text {nd }}\right)$ in this kind of species produced. In 2014, the total produced was 9,014.64 metric tons, and in 2014 the highest value was 494,471.70. The volume and value of frigate tuna (tulingan) ranked fifth $\left(5^{\text {th }}\right)$. In 2017 , the volume made was 451.91 metric tons, and in 2009, the highest value was 34,680.12. For grouper (lapu-lapu) and Indian mackerel (alumahan) was ranked first (1st). In 2015, the volume grew 1,047.77metric tons, and in 2009 the highest value was $168,660.74$. For Indian mackerel, ranked third $\left(3^{\text {rd }}\right)$ with the volume produced of $1,881.83$ metric tons in 2007, and the highest value was in 2011 that is 103,417.25.

For Indian sardines, it was ranked second $\left(2^{\text {nd }}\right)$. In 2017, the volume grew by 2,643.98 metric tons, and the highest value was $149,253.24$. For indo-pacific mackerel, it was ranked second $\left(2^{\text {nd }}\right)$ with the volume produced of $4,478.36$ metric tons in 2011, and the highest value was in 2012 that is 259,335.68. On round scad (galunggong) and skipjack (gulyasan). For round scad, it was ranked fourth $\left(4^{\text {th }}\right)$. In 2013, the volume grew by $2,505.19$ metric tons, and the highest value was 151,646.74. For skipjack, Capiz made this with minimal volume. For slipmouth (sapsap) and snapper (maya-maya). For slipmouth, it was ranked third $\left(3^{\text {rd }}\right.$ ) in this kind of species produced. In 2009, the volume grew 6,872.04 metric tons, and the highest value was 350,986.06 in 2012. For snapper, it was ranked first $\left(1^{\text {st }}\right)$, the highest volume produced was in 2012, which has 1,206.57 metric tons with a value of 191,878.33.

For Spanish mackerel, it was ranked third $\left(3^{\text {rd }}\right)$. In 2011 the volume made was 516.15 metric tons, and the highest value was $69,481.36$ in 2012. For squid, it was ranked third $\left(3^{\text {rd }}\right)$, the highest volume produced was in 2011, with $2,572.83$ metric tons with $219,868.89$. For Spanish mackerel, it was ranked third $\left(3^{\text {rd }}\right)$. In 2012 the volume made was $3,519.81$ metric tons, and the highest value was $298,335.77$ in 2012 . For yellowfin tuna, it was ranked fifth $\left(5^{\text {th }}\right)$ due to a decline in volume. In 2009, there were 474.69 metric tons produced.

\subsection{Species in Inland Fisheries}

For milkfish, Capiz was ranked fourth $\left(4^{\text {th }}\right)$. In 2012 the volume grew 12.65 metric tons, and the highest value was $1,114.64$ in 2012. For carp, it was ranked second $\left(2^{\text {nd }}\right)$. In 2013, produced 24.97 metric tons, and the value was 1,961. For mudfish, it was ranked second $\left(2^{\text {nd }}\right)$. In 2013 the volume made was 25.88 metric tons, and the highest value was 2,352.14 in 2012. For gourami, it was ranked second $\left(2^{\text {nd }}\right)$. In 2015, it produced 3.70 metric tons, and the value was 152.81. For freshwater catfish, it was ranked fifth $\left(5^{\text {th }}\right)$. In 2015 the volume grew 13.77 metric tons, and the highest value was 1,300.43 in 2015. For freshwater eel, Capiz has no made with this species. For tilapia, Capiz was ranked third $\left(3^{\text {rd }}\right)$. In 2013, the volume grew 44.66 metric tons, and the highest value was 3,062.52 in 2013. For catfish (hito), it was ranked second $\left(2^{\text {nd }}\right)$, and the highest volume produced was 26.22 metric tons in 2017, and the value was $2,552.24$

\subsection{Species in Aquaculture Fisheries}

For grouper, Capiz was ranked first $\left(1^{\text {st }}\right)$. In 2017, the volume grew 32.69 metric tons, and the highest value was $11,870.80$. For catfish, it was ranked second $\left(2^{\text {nd }}\right)$. In 2009 , is the highest volume made and was 29.02 metric tons, 


\section{AJAST}

Asian Journal of Applied Science and Technology (AJAST)

Volume 5, Issue 3, Pages 213-222, July-September 2021

and the highest value was 2,552.24 in 2017. For grouper, it was ranked second $\left(2^{\text {nd }}\right)$. The highest volume produced was 32.69 metric tons in 2017 , and the value was $11,870.80$.

For milkfish, Capiz was ranked first $\left(1^{\text {st }}\right)$. In 2017, is the highest volume made and was 33,242.74 metric tons, and the highest value was $2,793,311.62$. For mud crab, it was ranked first $\left(1^{\text {st }}\right)$. The highest volume produced was $2,048.37$ metric tons in 2017 , and the value was $853,046.57$. For mussels, it was ranked first $\left(1^{\text {st }}\right)$ in volume and value. In 2017, is the highest volume made and was 9,032.38 metric tons. Furthermore, for the oyster, it was ranked first $\left(1^{\text {st }}\right)$. The highest volume produced was 7,343.17 metric tons in 2017, and the value was 59,921.50.

For tiger prawns, Capiz was ranked first $\left(1^{\text {st }}\right)$ in this kind of species produced. In 2009, is the highest volume made and was $1,525.53$ metric tons, and the value was 495,364.40. For tilapia, it was ranked third $\left(3^{\text {rd }}\right)$. The highest volume produced was 283.69 metric tons in 2013, and the highest value was 18,376.05 in 2017. On white shrimp, it was ranked first $\left(1^{\text {st }}\right)$ in this kind of species produced. In 2017, is the highest volume made and was 11.39 metric tons, and the value was $1,977.34$.

For endeavor prawn, Capiz was ranked first $\left(1^{\mathrm{st}}\right)$, and the highest volume produced was 99.45 metric tons, and the value was 15,962.21. The results highlight that the province, including Roxas City, made less on various industries and species to other areas in the Western Visayas; second, the production of Aquaculture species such as milkfish, mud crab, mussels, oyster, tiger, white, and endeavor prawn Capiz producing well.

\subsection{Production by type of Aquafarm}

Fig 7 shows the volume and value of production by type of aquafarm in the Province of Capiz. In brackishwater fishpond, Capiz was ranked first $\left(1^{\text {st }}\right)$ with the highest volume produced of 36,466.96 in 2017 with a value of $4,015,889.89$.

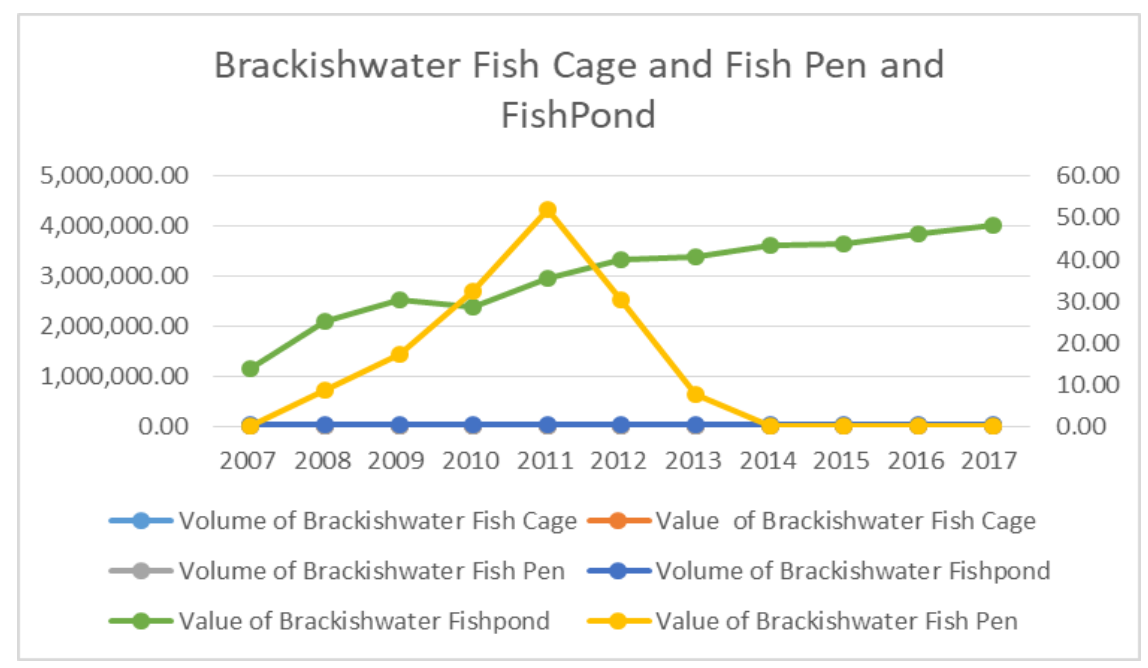

Fig.7. Showing the volume and value of fish cage and fish pen, and fishpond

Fig 8 shows the volume and value of production by type of aquafarm in the Province of Capiz. The data shows that the Capiz had a minimal volume produced in freshwater fishpond production. BFAR also validates that the provincial government-mandated fish cage owners to stop their operation because it causes perennial floods in the province. After all, the Panay River level becomes low. 


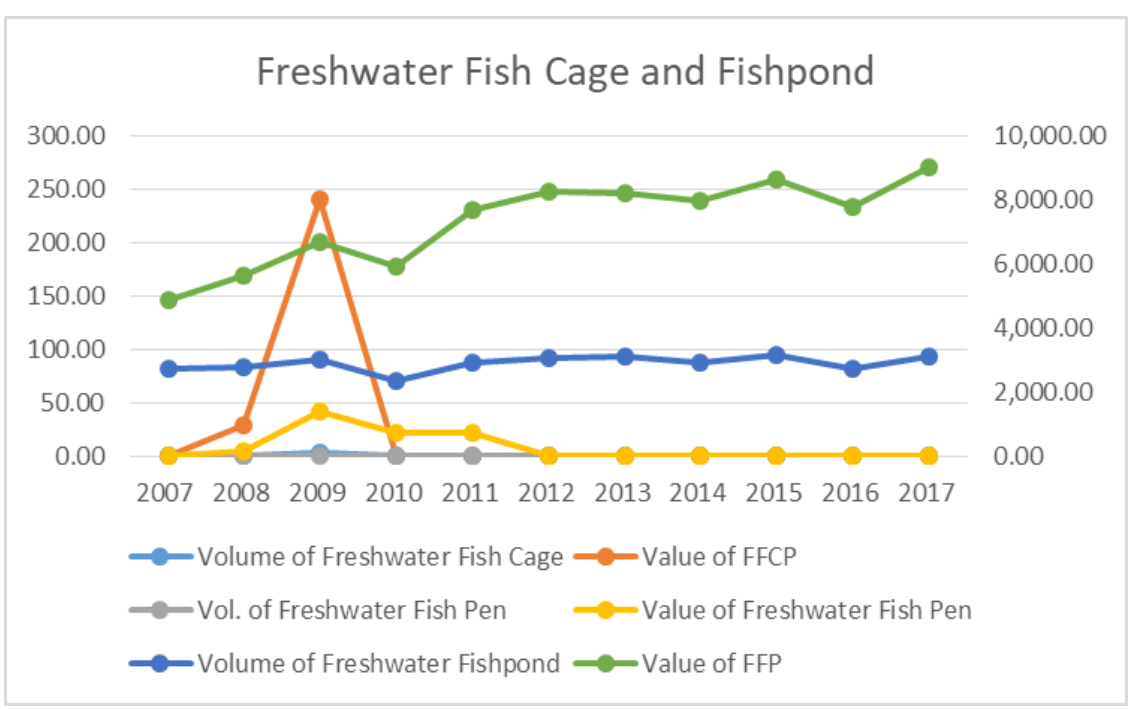

Fig.8. Showing the volume and value of freshwater fish cage and fishpond

Fig 9 shows the volume and value of production by type of aquafarm in the Province of Capiz. In the marine fish cage, Capiz was ranked third $\left(3^{\text {rd }}\right)$; the highest volume produced was 42.77 metric tons, with a value of $17,819.34$. On marine fish pen, the highest volume produced was 878.65 , with a value of $70,396.17$. Nevertheless, at present, there was no volume produced starting in 2014.

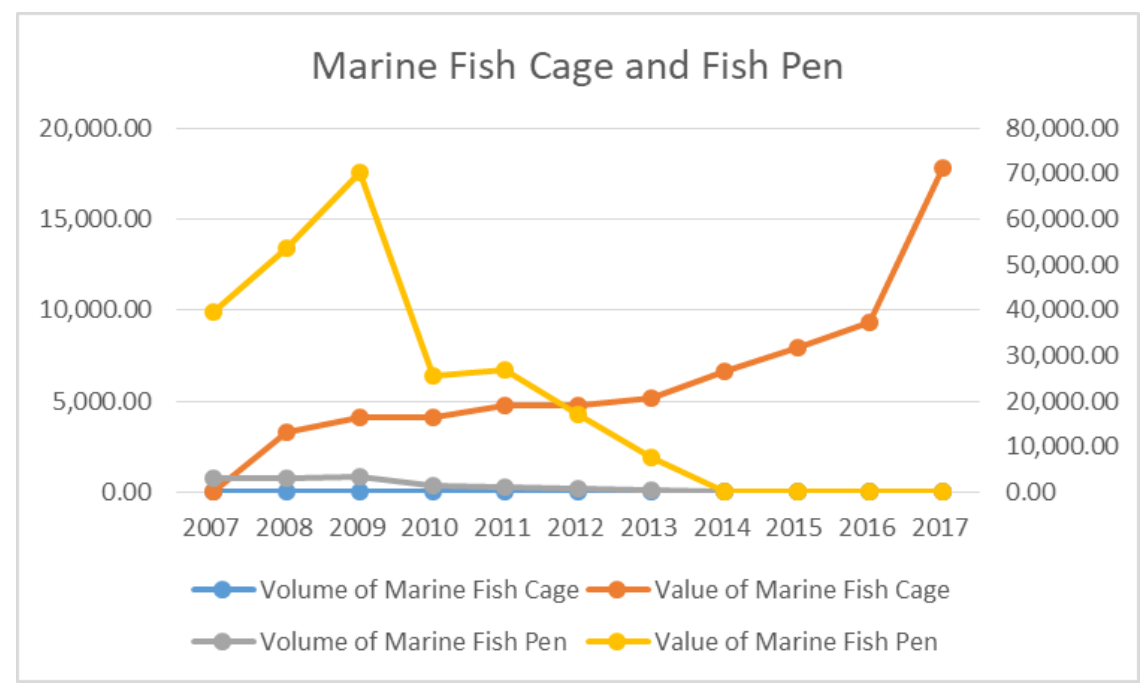

Fig.9. Showing the volume and value of marine fish cage and fish pen

Fig 10 shows the volume and value of production by type of aquafarm in the Province of Capiz. In oyster production, Capiz was ranked first $\left(1^{\text {st }}\right)$ with the highest volume produced of 7,343.17 and with a value of 59,921.50 in 2017. On mussel production, Capiz was also ranked first $\left(1^{\text {st }}\right)$ with the highest volume produced of $9,032.38$ with a value of $97,814.62$ in 2017.

Based on the data presented, the following findings are: (1) on the volume and value of production by type of aquafarm the Province of Capiz is producing high on the brackishwater fishpond; (2) in marine fish pen starting 2014 to 2017, there was no production; (3) in Oyster and Mussel, the province is commendable due to its volume produced because it was ranked first in the Western Visayas. 


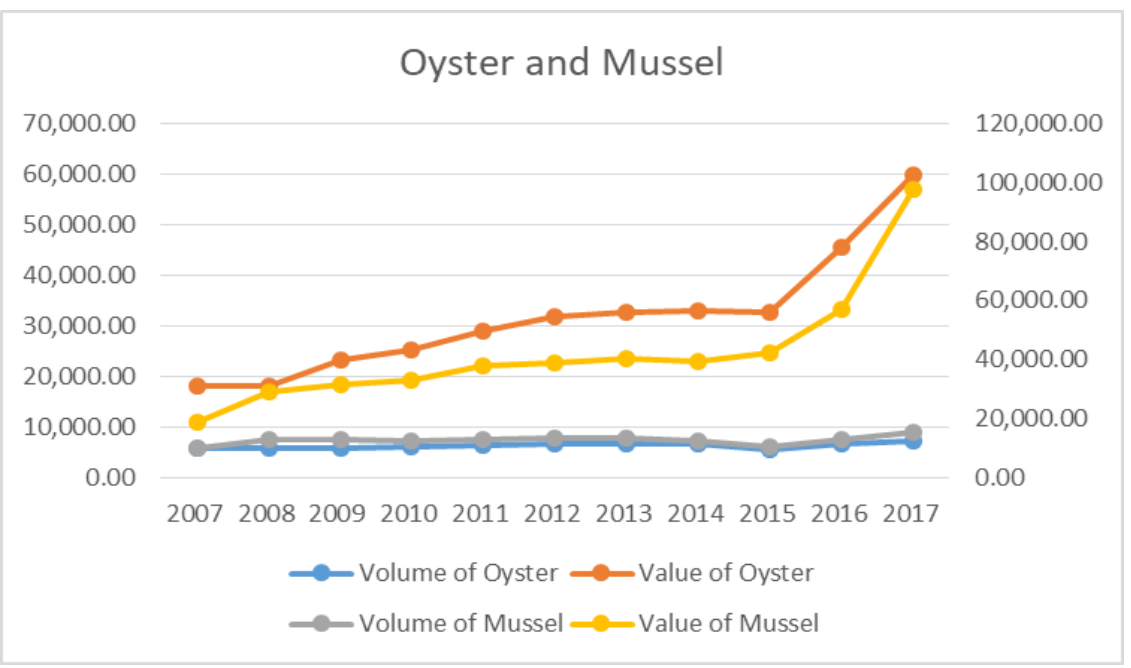

Fig.10. Showing the volume and value of oysters and mussels

\subsection{Top Fisheries Producing Provinces by Sector}

This section presented the data on the top fisheries producing provinces by sector. From the year 2005 to 2010 , the Province of Capiz was not part of the list.

\section{0-2012-Marine Municipal}

The province ranked seventh $\left(7^{\text {th }}\right)$ among nine (9) areas in the Philippines on the average annual production of $37,258.03$ with a percent share of 3.28 and a cumulative share of 38.26. On the other hand, the province ranked eighth $\left(8^{\text {th }}\right)$ among nine (9) areas in the Philippines in terms of the average annual production of $35,840.58$ metric tons with a percent share of 3.27 and a cumulative share of 40.65 .

\section{5-2017-Marine Municipal}

The Province of Capiz was ranked ninth $\left(9^{\text {th }}\right)$ among nine provinces in the Philippines in terms of the average annual production of $28,468.93$ metric tons with a percent share of 2.89 and cumulative share of 41.70 .

\section{Conclusions and Recommendations}

Among fishing industries where the Capiz involved with Commercial, Marine Municipal, Inland Municipal produced poorly. On the other hand, the province is doing well in aquaculture species production like milkfish, mud crab, mussel, oyster, white shrimp, tiger, and endeavor prawn produced by an identified municipality Ivisan, Pontevedra, Pilar, Panay, President Roxas, and Roxas City.

Brackishwater fishpond production based on volume and value, the Province of Capiz is doing well due to the increasing volume produced for the last eleven (11) years. The claim of the Roxas City government as the Seafood Capital of the Philippines has no basis on various sources like policy passed by the Provincial and City government. The baseline data used by the researchers quantify and prove that Roxas City is not producing seafood abundantly. The branding of Roxas City as the Seafood Capital of the Philippines is a myth based on the researchers' investigation through various analyses such as on the trends of volume and value, types of production, and species. Hence, the production stage is not from Roxas City, but it is only a gateway of logistics from neighboring 


\section{AJAST}

Asian Journal of Applied Science and Technology (AJAST)

Volume 5, Issue 3, Pages 213-222, July-September 2021

municipalities and provinces. Roxas City, specifically the Libas Fishing Port, delivered and distributed to other parts of the country and local businesses.

With the above conclusions, the following recommendations are: first, the policymakers in the Province of Capiz may formulate a policy or revised any provisions to support the claim that Roxas City is the Seafood Capital of the Philippines; second, the growers and entrepreneurs may look into sustainable fishing basically in the aquaculture side to improve its production and value; third, the higher education institutions may study the supply chain management of aquaculture products for value-adding; fourth, may the BFAR of the Province of Capiz may look into consideration for sustaining and developing the competitive edge of the province with regards to aquaculture products and improving its value proposition and studying and producing other species also available in the area; and lastly, improve the fishing tourism industry of the Province of Capiz through a social marketing plan, and inclusivity of the claims.

\section{Declarations}

\section{Source of Funding}

This research did not receive any grant from funding agencies in the public, commercial, or not-for-profit sectors.

\section{Competing Interests Statement}

The authors declare no competing financial, professional and personal interests.

\section{Consent for publication}

Authors declare that they consented for the publication of this research work.

\section{Data Availability}

Authors are willing to share the data and materials based on relevant needs.

\section{References}

[1] Bureau of Fisheries and Aquatic Resources National Program for Municipal Fishing 2007-2017.

[2] Fisheries Statistics Division, PSA (www.psa.gov.ph).

[3] Fisheries Statistics of the Philippines, 2007-2017.

[4] Food and Nutrition Research Institute Website. 